\title{
The utility of detecting ovulation to predict success in ovulation induction and intrauterine insemination cycles - a prospective observational study
}

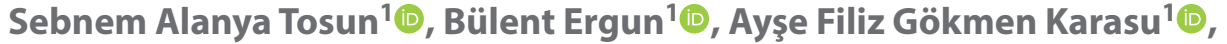 \\ Enis Özkaya ${ }^{2}$, , Tuğba Gürbüz ${ }^{1}$ (D) \\ ${ }^{1}$ Department of Obstetrics and Gynecology, Istanbul University Istanbul Faculty of Medicine, Istanbul, Turkey \\ ${ }^{2}$ Department of Obstetrics and Gynecology, Health Sciences University Zeynep Kamil Women and Children's \\ Diseases Training and Research Hospital, istanbul, Turkey
}

\begin{abstract}
Objectives: The success of ovulation induction-intrauterine insemination (OI-IUI) procedures may be limited by the absence of ovulation detection. The aim of this study was to evaluate the empirical use of ultrasonography and luteal phase progesterone (P4) as ovulation indicators and determine its effect on pregnancy outcome in OI-IUI cycles.

Material and methods: This prospective observational study, which was performed in a university setting, included 107 women with unexplained infertility. Following OI, IUI was performed 36 hours after human chorionic gonadotropin (hCG). P4 was measured 72-96 hours after hCG. At the same time, the appearance of ovaries and signs indicative of ovulation, which are decreased follicle dimensions, irregularity of follicular walls, and the presence of free fluid in the Douglas pouch, were noted.

Results: In 58 patients (54.2\%), ovulation was detected at the P4 level of $>10 \mathrm{ng} / \mathrm{mL}$. Eighty-nine patients had ultrasound images suggestive of ovulation. However, only 50 of these were confirmed ovulation as indicated using P4. Implantation was observed in a total of 13 patients (12.1\%). All patients were in the ovulation detected group with P4 > 10 ng/mL (AUC: $0.750 ; p=0.004)$. $P 4$ of $>21.5 \mathrm{ng} / \mathrm{mL}$ detected successful ovulation and was strongly associated with implantation with $77 \%$ sensitivity and $61 \%$ specificity (OR: $9.9 ; 95 \% \mathrm{Cl}: 2.4-41.2)$. Body mass index (BMI) $>23.9 \mathrm{~kg} / \mathrm{m}^{2}$ was a reliable anovulation indicator as a secondary outcome (AUC: 0.696; $p=0.02$ ).

Conclusions: In $45.8 \%$ of the patients, ovulation did not occur even with OI treatment. The association of progesterone measurement and ovarian ultrasound scanning between 72 and 96 hours after hCG treatment can be used to detect ovulation. In doing so, we can find the optimal treatment for patients with infertility in their next cycle.

Key words: ovulation; ovulation induction; progesterone; implantation; intrauterine insemination
\end{abstract}

Ginekologia Polska 2021; 92, 12: 860-864

\section{INTRODUCTION}

One in six couples is affected by fertility disorders and approximately $30 \%$ of the patients in reproduction physicians experience unexplained infertility [1]. Ovulation induction (OI) followed by intrauterine insemination (IUI) is the first choice treatment of idiopathic infertility due to its low risk and cost-effectiveness [2]. The success of OI-IUI may vary from 8 to $20 \%$ according to maternal age, the follicular stimulation protocol, the timing of IUI, and the verification of ovulation [3]. Considering the lack of ovulation verification following OI-IUI in current clinical practice, there is doubt that a luteinised unruptured follicle, despite treatment, may limit the success of the procedure [4].

IUI procedure should be performed at the time of follicle rupture [5]. Real-time and non-invasive evidence of ovulation offered by ovarian ultrasound has been previously described in women [6]. It involves disappearance or a decrease in follicle dimension, irregularity of follicular walls, and the presence of free fluid in the Douglas pouch. However, the use of ultrasonographic criteria for the detec-

\footnotetext{
Corresponding author:

Sebnem Alanya Tosun

Department of Obstetrics and Gynecology, Istanbul University Istanbul Faculty of Medicine, Istanbul, Turkey

e-mail: sebnem_alanya@hotmail.com
} 
tion of ovulation is not a routine step for OI-IUI cycles in current practice [5].

Luteal progesterone (P4) is essential for endometrial receptivity and pregnancy maintenance [7]. Therefore, plasma $\mathrm{P} 4$ concentration is a low cost and reliable indicator of ovulation in humans. The level of $\mathrm{P} 4$ remains under $1 \mathrm{ng} / \mathrm{mL}$ during the follicular phase and progressively increases following the luteinising hormone (LH) surge, reaching maximum values between days seven and eight post-ovulation [1].

\section{Objectives}

In this study, our objective was to examine whether luteal phase progesterone levels and ultrasound indicators of ovulation on TVUS could predict successful implantation and clinical pregnancy in $\mathrm{OI}+\mathrm{IUI}$ cycles.

\section{MATERIAL AND METHODS}

This was a prospective observational study conducted in a university setting. The study was approved by the Ethics Committee of Istanbul University School of Medicine (Date: June $21^{\text {st }}, 2013$, No.12).

\section{Participant characteristics}

One hundred fifteen patients undergoing OI-IUI treatment in Istanbul University infertility outpatient clinics were initially enrolled in the study. All participants underwent a detailed gynaecology examination, comprehensive infertility assessment including hysterosalpingography (HSG), ovarian reserve tests, mid-luteal P4 concentrations, and semen analysis. The inclusion criteria of the study were as follows: failure to conceive for at least 12 months of regular intercourse, spontaneous menstrual cycle regularity ranging from 21 to 35 days, bilateral tubal patency detected with HSG, basal (menstrual cycle day 3), follicle-stimulating hormone (FSH) levels under $15 \mathrm{IU} / \mathrm{L}$, and normal semen characteristics according to the World Health Organization [8]. The exclusion criteria were as follows: moderate to severe endometriosis diagnosed as American Fertility Society, stage III or IV; the presence of a congenital uterine anomaly: abnormal prolactin or thyroid hormone levels; and male factor. Body mass indexes (BMI) of the patients were also noted.

\section{Ovulation induction plus intrauterine insemination}

Transvaginal ultrasound (TVUS) examinations were performed on all participants on day three of their menstrual cycle. After ruling out persistent follicles, they were treated with either clomiphene citrate (CC) for five days (Klomen, Kocak Farma, Turkey) or 75 IU recombinant FSH (Gonal-F, Organon, Turkey). Endometrial thickness and ovarian response were evaluated using TVUS starting from cycle day 7 . If the diameter of any follicle did not reach $10 \mathrm{~mm}$ on cycle day nine, the gonadotropin (Gn) dose was increased by $50 \%$.
If the diameter of the leading follicle reached $12 \mathrm{~mm}$, the dose of gonadotropin remained the same until the day of human chorionic gonadotropin (hCG) trigger. When the dominant follicle reached $18 \mathrm{~mm}$, triggering of ovulation by $250 \mu \mathrm{cg}$ recombinant hCG (Ovitrelle, Serono, Turkey) was performed.

Sperm for insemination was obtained via masturbation. Whole semen was washed and complemented with $0.5 \%$ human serum albumin in a $5-\mathrm{mL}$ Falcon conical tube. This integrity was centrifuged at $1500 \mathrm{rpm}$ for $5 \mathrm{~min}$. The supernatant was rejected, and the pellet resuspended in $0.5 \mathrm{~mL}$ medium. $0.5 \mathrm{~mL}$ medium was coated on the suspension of sperm and the tube was sloped at 45 degrees angle and incubated at $37^{\circ} \mathrm{C}$ for at least $40 \mathrm{~min}$. The tube was set gently, and the upper interface was aspirated with a Pasteur pipette. The supernatants of both tubes were collected for 0.4 cc sperm samples.

Cycles were cancelled when 3 or more dominant follicles were obtained and/or estradiol levels exceeded $1500 \mathrm{pg} / \mathrm{mL}$. IUI was performed $36 \mathrm{~h}$ after the $\mathrm{hCG}$ application using a disposable intrauterine catheter. Luteal phase progesterone support was not administered. Serum P4 was measured $96 \mathrm{~h}$ after hCG administration. This was designated as the luteal phase P4. At the same time ( $96 \mathrm{~h}$ after hCG), TVUS was performed, and the appearance of ovaries and signs indicative of ovulation were noted.

When serum P4 was measured $>10 \mathrm{ng} / \mathrm{mL}$, it was accepted as ovulation [9]. Twelve days after the IUI procedure, beta-hCG was measured. Serum beta-hCG levels above > $10 \mathrm{mlU} / \mathrm{mL}$ were accepted as "implantation". Six weeks after the IUI procedure, the presence of intrauterine fetal cardiac activity was accepted as "clinical pregnancy".

\section{Statistical analysis}

The statistical evaluation of our data was performed using the Statistical Package for the Social Sciences (SPSS version 15.0) (IBM Corp. Armonk, NY, USA) statistical software. The Kolmogorov-Smirnov test was used to assess the normality distributions of continuous variables. Regression and correlation analyses were performed to assess the relationship of variables concerning "ovulation", "implantation", and "clinical intrauterine pregnancy". Continuous variables were compared using the Mann Whitney-U test between groups with and without clinical pregnancy. We performed receiver operating characteristic curve (ROC) analysis to show the predictive value of the variables "Luteal P4" and "BMI" included in the model in regarding ovulation. The analysis of ROC curves provides values for the area under the curve (AUC), which vary between 0.5 and 1.0, and may be evaluated as estimations of the global classification ability of the model. Values are given in terms of $95 \%$ confidence intervals $(\mathrm{Cls})$ and $\mathrm{p}<0.05$ as statistical significance. 


\section{RESULTS}

Initially, 115 patients were enrolled in this prospective observational study. A total of eight patients were excluded from the study; two patients did not develop follicles $>18 \mathrm{~mm}$, one patient could not adapt to treatment, two patients had cycle cancellations due to multi-follicular development, and three patients exceeded 96 hours after hCG. One hundred seven patients were included in the final analysis.

In our cohort, the mean age and BMI of the participants were $28.3 \pm 4$ years and $25.3 \pm 3.9 \mathrm{~kg} / \mathrm{m}^{2}$, respectively. The mean basal hormone levels were as follows: $\mathrm{FSH}$ : $5.9 \pm 2.6 \mathrm{mlU} / \mathrm{mL}, \mathrm{LH}: 7.1 \pm 5.2 \mathrm{IU} / \mathrm{L}$, and anti-mullerian hormone $(\mathrm{AMH}): 3.5 \pm 3.2 \mathrm{ng} / \mathrm{mL}$. A total of 46 patients received $50 \mathrm{mg}$ CC-IUI, 61 patients received Gn-IUI treatment.

Ovulation confirmed by luteal P4 $>10 \mathrm{ng} / \mathrm{mL}$ was verified in 58 patients out of 107 . The patients were grouped according to the treatment protocols as the CC-IUI group (22/46, 47.8\%) and the Gn-IUI group (36/61, 59\%). The difference between the CC-IUI and Gn-IUI treatment groups was not statistically significant $(p=0.238)$. Eighty-nine patients out of 107 had ultrasound images suggestive of ovulation on TVUS; however, only 50 of these were confirmed ovulation confirmed according to serum P4 levels (Tab. 1).

Implantation was observed in a total of 13 patients (12.1\%). All patients were in the ovulation detected group with luteal phase P4 > $10 \mathrm{ng} / \mathrm{mL}$ (AUC: $0.750 ; \mathrm{p}=0.004$ ). ROC analysis showed that luteal phase P4 levels of $>21.5 \mathrm{ng} / \mathrm{mL}$ detected successful implantation with $77 \%$ sensitivity and 61\% specificity (OR: 9.9; 95\% Cl, 2.4-41.2) (Fig. 1 and 2). Five patients in the CC-IUI group and five in the Gn-IUI group had fetal cardiac activity-positive pregnancies. Luteal phase P4 levels of $21.5 \mathrm{ng} / \mathrm{mL}$ were found significant in clinical pregnancy prediction with $90 \%$ sensitivity and $61 \%$ specificity (AUC: $0.810 ; p=0.001$ ). Two patients in the Gn-IUI group developed ectopic pregnancies. One was treated with single-dose methotrexate, the other underwent laparoscopic salpingectomy. One patient who achieved pregnancy in

\begin{tabular}{|c|c|c|c|}
\hline $\begin{array}{l}\text { Progesterone } \\
{[\mathrm{ng} / \mathrm{mL}]}\end{array}$ & $\begin{array}{l}\text { Endometrial } \\
\text { measurement } \\
{[\mathrm{mm}]}\end{array}$ & $\begin{array}{l}\text { Evidence of } \\
\text { ovulation on } \\
\text { TVUSG* (n) }\end{array}$ & $\begin{array}{l}\text { Evidence of } \\
\text { anovulation on } \\
\text { TVUSG** (n) }^{*}\end{array}$ \\
\hline \multirow{2}{*}{$\begin{array}{l}\text { Progesterone } \\
>10 \mathrm{ng} / \mathrm{mL}\end{array}$} & $<8 \mathrm{~mm}$ & 1 & 2 \\
\hline & $>8 \mathrm{~mm}$ & 49 & 6 \\
\hline \multirow{2}{*}{$\begin{array}{l}\text { Progesterone } \\
<10 \mathrm{ng} / \mathrm{mL}\end{array}$} & $<8 \mathrm{~mm}$ & 2 & 1 \\
\hline & $>8 \mathrm{~mm}$ & 37 & 9 \\
\hline Total & & 89 & 18 \\
\hline
\end{tabular}

*Disappearance or decrease in follicle dimensions, irregularity of follicular walls or presence of free fluid in the Douglas pouch is described as evidence of ovulation on TVUSG:

**Persistence of follicle is described as evidence of anovulation on TVUSG the Gn-IUI group developed mild ovarian hyperstimulation syndrome and was treated conservatively.

As a secondary outcome, $\mathrm{BMI}$ was a reliable indicator of anovulation (AUC: 0.696; $p=0.02$ ) (Tab. 2). Except for this, progesterone on the day of the $\mathrm{hCG}$ trigger was $>1 \mathrm{ng} / \mathrm{mL}$ in

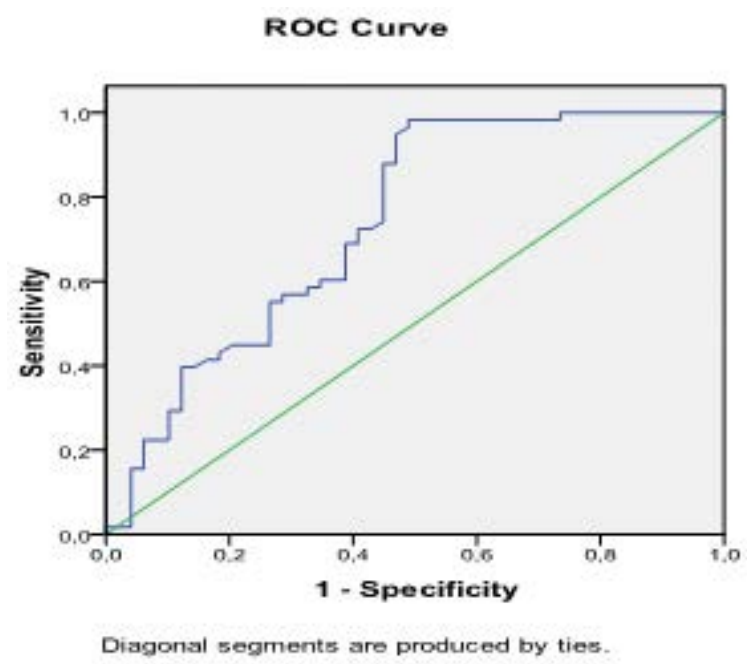

Figure 1. The relation of luteal phase progesteron and ovulation is shown above. Luteal phase P4 level of $21.5 \mathrm{ng} / \mathrm{mL}$ was found significant in clinical pregnancy prediction with $90 \%$ sensitivity and $61 \%$ specifity (AUC: $0.810 ; p=0.001$ )

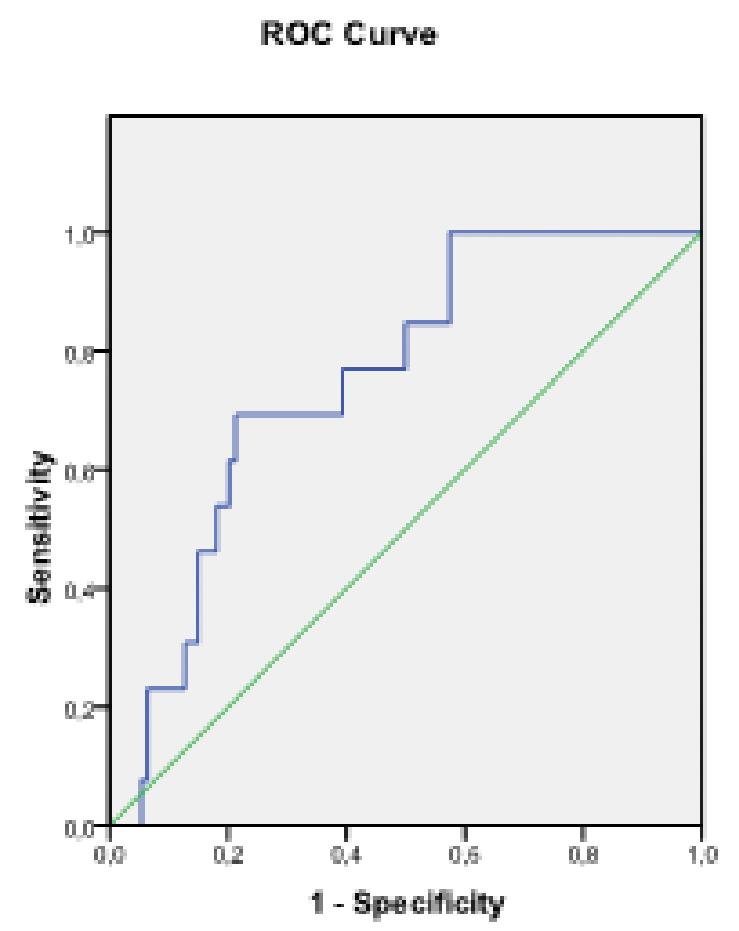

Figure 2. The correlation between luteal phase progesterone and implantation is shown. The ROC analysis showed that luteal phase P4 level of $>21.5 \mathrm{ng} / \mathrm{mL}$ detected successful implantation with $77 \%$ sensitivity and $61 \%$ specifity (OR: 9.9 [2.4-41.2]) 
12 patients. None of these patients with progesterone levels above $1 \mathrm{ng} / \mathrm{mL}$ achieved implantation/pregnancy despite two of these patients having signs suggesting ovulation on TVUS.

According to our correlation analysis, ovulation was negatively correlated with $\mathrm{BMI}(r=-0.293 ; \mathrm{p}=0.002)$ and serum FSH $(r=-0.204 ; p=0.04)$, and positively correlated with hCG day P4 ( $r=0.411 ; p<0.001)$, luteal phase P4 ( $r=0.347$; $\mathrm{p}<0.001)$. Implantation was negatively correlated with serum FSH levels $(r=-0.193 ; p=0.04)$ and positively correlated with ovulation $(r=0.342 ; p<0.001)$, serum AMH $(r=0.545$; $p=0.004)$, and luteal phase P4 $(r=0.251 ; p=0.009)$ (Tab. 3). Clinical pregnancy was negatively correlated with FSH $(r=-0.195 ; p=0.04)$ and positively correlated with luteal phase P4 ( $r=0.296 ; p=0.002)$ (Tab. 4). Although luteal phase P4 was statistically significant in the prediction of ovulation, implantation, and clinical pregnancy, ultrasound verification was not found significant for these parameters (ovulation:

\begin{tabular}{|l|l|l|l|l|}
\hline \multicolumn{3}{|c|}{ Table 2. Luteal phase progesterone and BMI in predicting ovulation } \\
\hline Predictor & AUC & Cut-off value & $\begin{array}{l}\text { Sensitivity } \\
(\%)\end{array}$ & $\begin{array}{l}\text { Specificity } \\
(\%)\end{array}$ \\
\hline LFP & $\begin{array}{l}0.739, \\
p<0.001\end{array}$ & $10.3 \mathrm{ng} / \mathrm{mL}$ & 98 & 51 \\
\hline BMI & $\begin{array}{l}0.657, \\
p=0.005\end{array}$ & $23.9 \mathrm{~kg} / \mathrm{m}^{2}$ & 71 & 50 \\
\hline
\end{tabular}

AUC — area under the curve; BMI — body mass index; LFP — luteal phase progesterone $r=0.247 ; p=0.01 ;$ implantation: $r=0.221 ; p=0.02$; clinical pregnancy: $r=0.231 ; p=0.02$ ).

\section{DISCUSSION}

The success of OI-IUI procedures may be limited by the absence of ovulation detection. In this prospective observational study, ovulation did not occur even with Ol treatment in $45.8 \%$ of the patients. The association of progesterone measurement and ovarian ultrasound scanning between 72 and 96 hours after hCG treatment can be used to detect ovulation.

According to the present study, P4 levels above $21.3 \mathrm{ng} / \mathrm{mL}$ detected successful implantation with $77 \%$ sensitivity and $61 \%$ specificity, and clinical pregnancy with $90 \%$ sensitivity and $61 \%$ specificity. In the study by Perkins et al., a P4 threshold level lower than $45 \mathrm{ng} / \mathrm{mL}$ was coherent with a nonviable pregnancy in patients treated with assisted reproduction [10]. In the study by Arce et al. [11], mid-luteal P4 levels $>7.9 \mathrm{ng} / \mathrm{mL}$ were related to live births during ovulation induction. In accordance with these studies, the progesterone levels seem to be correlated with viable pregnancies both in normal menstrual cycles and ovulation induction cycles. However, there are also conflicting studies. Costello et al., speculated on a forecasting model of mid-luteal P4 levels in patients undergoing OI-IUI and concluded that elevated mid-luteal serum P4 levels were not related to higher pregnancy rates [12]. Yildirim et al. [13] showed a positive relation between luteal phase $\mathrm{P} 4$ and

Table 3. Correlation values for implantation and other variables

\begin{tabular}{|c|c|c|c|c|c|c|c|c|c|c|c|c|}
\hline \multicolumn{13}{|c|}{ Implantation } \\
\hline & Age & Gravidity & Parity & BMI & $\begin{array}{l}\text { Primary/secondary } \\
\text { infertility }\end{array}$ & FSH & LH & AMH & $\begin{array}{l}\text { P on } \\
\text { HCG day }\end{array}$ & Ovulation & LFP & $\begin{array}{l}\text { Fetal Cardiac } \\
\text { Activity }\end{array}$ \\
\hline *rValue & -0.089 & 0.025 & -0.05 & -0.192 & -0.019 & -0.187 & 0.17 & 0.332 & -0.184 & 0.339 & 0.295 & 0.895 \\
\hline${ }^{* *}$ P value & 0.0375 & 0.808 & 0.619 & 0.055 & 0.854 & 0.061 & 0.09 & 0.113 & 0.065 & 0.001 & 0.03 & $<0.001$ \\
\hline
\end{tabular}

*Correlation coefficient; ** The level of statistical significance; AMH — anti-mullerian hormone; BMI — body mass index; FSH, follicle-stimulating hormone; LH - luteinizing hormone; $\mathrm{P}$ - progesterone

Table 4. Comparison of the clinical data of the clinical pregnancy group and the group without pregnancy

\begin{tabular}{|l|l|l|l|l|l|l|l|}
\hline & \multicolumn{2}{l}{ CP*(+) } & CP (-) & \\
\hline & Median & SD & IQR & Median & SD & IQR & P (MWU**) \\
\hline Age [years] & 27 & 4.1 & 7 & 28 & 4.7 & 7 & 0.9 \\
\hline BMI $\left[\mathrm{kg} / \mathrm{m}^{2}\right]$ & 22.5 & 4.2 & 3.8 & 25 & 3.9 & 4.9 & 0.08 \\
\hline FSH $[\mathrm{mlU} / \mathrm{mL}]$ & 3.8 & 2.9 & 3.9 & 5.9 & 2.5 & 2.5 & 0.03 \\
\hline AFC & 8 & 4.9 & 7.8 & 8 & 6.1 & 8.5 & 0.6 \\
\hline Progesterone 1 & 6 & 0.2 & 0.3 & 0.8 & 1.9 & 0.9 & 0.1 \\
\hline Progesterone 2 & 33.4 & 8.6 & 14.1 & 15.5 & 12.1 & 16.9 & 0.001 \\
\hline Endometrial Thickness & 13 & 2.8 & 3 & 11 & 2.6 & 4 & 0.1 \\
\hline
\end{tabular}

${ }^{*} \mathrm{CP}$ - Clinical pregnancy; ${ }^{* *} \mathrm{MWU}$ - Mann-Whitney U; IQR — interquartile range; BMI — body mass index; FSH — follicle-stimulating hormone; SD — standard deviation 
clinical pregnancy rates in women with mixed diagnoses, as did Arce et al. [11] in a group of anovulatory women.

Pregnancy rates per OI-IUI cycles in the literature are quite low compared with in vitro fertilization (IVF) and favourable scores are usually achieved in 3 consecutive cycles [14]. As it is not known whether ovulation occurs in all OI-IUI cycles, it leads to reduced success, time loss, and increased cost in patients without ovulation despite OI-IUI.

IUI protocols may vary among centres and among practising physicians, even in an individual centre. A luteal phase P4 level is obtained at the initial assessment of the infertile couple; however, routine establishment of P4 levels is not established in each cycle. Follicular development has been evaluated using TVUS, but physicians are not curious to observe the ovulation routinely, either by TVUS or by progesterone measurement in OI-IUI cycles [5]. The hCG trigger is administered according to serial TVUS findings and this is performed at an earlier time than one would expect a follicle to mature in a natural cycle. In patients who received OI-IUI treatment, ovulation was confirmed in only $54.2 \%$ by luteal P4 measurement. The P4 threshold was accepted as $10 \mathrm{ng} / \mathrm{mL}$ for ovulation to exclude luteal phase defect [9]. In $45.8 \%$ of the patients, ovulation was not verified even with ovulation induction treatment. All implantations were in the ovulation detected group with luteal phase P4 > $10 \mathrm{ng} / \mathrm{mL}$. P4 evaluation in the luteal phase is convenient and an inexpensive measurement. By combining it with ultrasound scanning 72-96 hours after the hCG injection day, we can find the optimal treatment for patients with infertility in their next cycle.

The mean BMI of our patients was $25.3 \pm 3.9 \mathrm{~kg} / \mathrm{m}^{2}$. In our ROC analysis model, we calculated that BMI $>23.9 \mathrm{~kg} / \mathrm{m}^{2}$ was a reliable indicator of anovulation. Similarly, it was shown that obesity was related to lower oocyte retrieval during assisted reproductive technologies, lower clinical pregnancy rates, and higher pregnancy loss phenomenon $[15,16)$.

A limitation of this study is the inclusion of two different protocols for OI with CC and rFSH. Although both medications work in different physiologies, statistically there is no difference between these treatment groups in terms of ovulation, implantation, and clinical pregnancy rates. Further studies with larger cohorts are needed to prove our results.

\section{CONCLUSIONS}

Measuring serum luteal P levels combined with TVUS in IUI cycles can aid in determining success rates. Ovulation detection in OI-IUI cycles may be helpful in planning the next IUI cycle or directing patients directly to IVF.

\section{Acknowledgements}

We would like to thank M.K. Ozel for helping in the data analysis and D.F. Chapman, BSc, for editing the article.

\section{Conflict of interest}

All authors declare no conflict of interest.

\section{REFERENCES}

1. Hansen KR, Eisenberg E, Baker V, et al. NICHD Reproductive Medicine Network. Midluteal progesterone: a marker of treatment outcomes in couples with unexplained infertility. J Clin Endocrinol Metab. 2018; 103(7): 2743-2751, doi: 10.1210/jc.2018-00642, indexed in Pubmed: 29767754.

2. Goverde AJ, McDonnell J, Vermeiden JP, et al. Intrauterine insemination or in-vitro fertilisation in idiopathic subfertility and male subfertility: a randomised trial and cost-effectiveness analysis. Lancet. 2000; 355(9197): $13-$ 18, doi: 10.1016/S0140-6736(99)04002-7, indexed in Pubmed: 10615885.

3. Thomas S, Sebastian T, Karthikeyan M, et al. Effectiveness of spontaneous ovulation as monitored by urinary luteinising hormone versus induced ovulation by administration of human chorionic gonadotrophin in couples undergoing gonadotrophin-stimulated intrauterine insemination: a randomised controlled trial. BJOG. 2019; 126(Suppl 4): 58-65, doi: 10.1111/1471-0528.15830, indexed in Pubmed: 31169952.

4. Oublan $\mathrm{H}$, Amarin $\mathrm{Z}$, Nawasreh $\mathrm{M}$, et al. Luteinized unruptured follicle syndrome: incidence and recurrence rate in infertile women with unexplained infertility undergoing intrauterine insemination. Hum Reprod. 2006; 21(8): 2110-2113, doi: 10.1093/humrep/del113, indexed in Pubmed: 16613885.

5. Cantineau AEP, Janssen MJ, Cohlen BJ, et al. Synchronised approach for intrauterine insemination in subfertile couples. Cochrane Database Syst Rev. 2014(12): CD006942, doi: 10.1002/14651858.CD006942.pub3, indexed in Pubmed: 25528596.

6. Ecochard R, Marret $H$, Rabilloud M, et al. Sensitivity and specificity of ultrasound indices of ovulation in spontaneous cycles. Eur J Obstet Gynecol Reprod Biol. 2000; 91(1): 59-64, doi: 10.1016/s03012115(99)00249-3, indexed in Pubmed: 10817880.

7. Large MJ, DeMayo FJ. The regulation of embryo implantation and endometrial decidualization by progesterone receptor signaling. Mol Cell Endocrinol. 2012; 358(2): 155-165, doi: 10.1016/j.mce.2011.07.027, indexed in Pubmed: 21821095.

8. Cooper TG, Noonan E, von Eckardstein S, et al. World Health Organization reference values for human semen characteristics. Hum Reprod Update. 2010; 16(3): 231-245, doi: 10.1093/humupd/dmp048, indexed in Pubmed: 19934213.

9. Cédrin-Durnerin I, Isnard T, Mahdjoub S, et al. Serum progesterone concentration and live birth rate in frozen-thawed embryo transfers with hormonally prepared endometrium. Reprod Biomed Online. 2019; 38(3): 472-480, doi: 10.1016/j.rbmo.2018.11.026, indexed in Pubmed: 30642638.

10. Perkins SL, Al-Ramahi M, Claman P. Comparison of serum progesterone as an indicator of pregnancy nonviability in spontaneously pregnant emergency room and infertility clinic patient populations. Fertil Steril. 2000; 73(3): 499_ 504, doi: 10.1016/s0015-0282(99)00543-9, indexed in Pubmed: 10689002.

11. Arce JC, Balen A, Platteau P, et al. Mid-luteal progesterone concentrations are associated with live birth rates during ovulation induction. Reprod Biomed Online. 2011; 22(5): 449-456, doi: 10.1016/j.rbmo.2011.01.006, indexed in Pubmed: 21397560.

12. Costello MF, Emerson S, Lukic J, et al. Predictive value of mid luteal progesterone concentration before luteal support in controlled ovarian hyperstimulation with intrauterine insemination. Aust N Z J Obstet Gynaecol. 2004; 44(1): 51-56, doi: 10.1111/j.1479-828X.2004.00160.x, indexed in Pubmed: 15089869.

13. Yildirim G, Turkgeldi LS, Koroglu N. Predictive factors for pregnancy outcome following controlled ovarian stimulation and intrauterine insemination. J Pak Med Assoc. 2017; 67(3): 422-427, indexed in Pubmed: 28303993.

14. Farquhar C, Liu E, Armstrong S, et al. Intrauterine insemination with ovarian stimulation versus expectant management for unexplained infertility (TUI): a pragmatic, open-label, randomised, controlled, two-centre trial. Lancet. 2018; 391(10119): 441-450, doi: 10.1016/s0140-6736(17)324066, indexed in Pubmed: 29174128.

15. Jungheim ES, Lanzendorf SE, Odem RR, et al. Morbid obesity is associated with lower clinical pregnancy rates after in vitro fertilization in women with polycystic ovary syndrome. Fertil Steril. 2009; 92(1): 256-261, doi: 10.1016/j.fertnstert.2008.04.063, indexed in Pubmed: 18692801.

16. Fedorcsák P, Dale PO, Storeng R, et al. Impact of overweight and underweight on assisted reproduction treatment. Hum Reprod. 2004; 19(11): 2523-2528, doi: 10.1093/humrep/deh485, indexed in Pubmed: 15319380. 